\title{
Synthesis and Performance Evaluation of Chitosan/zinc Oxide Nanocomposite as a Highly Efficient Adsorbent in the Removal of Reactive Red 198 From Water
}

Najmeh Amirmahani

Kerman University of Medical Sciences

Hakimeh Mahdizadeh ( $\sim$ H.mahdizadeh2018@gmail.com )

Kerman University of Medical Sciences https://orcid.org/0000-0001-5035-8607

Neda Seyedi

Jiroft University of Medical Sciences

Alireza Nasiri

Kerman University of Medical Sciences

Ghazal Yazdanpanah

Kerman University of Medical Sciences

\section{Research Article}

Keywords: Chitosan, Chitosan/ZnO nanocomposite, Reactive red 198, High removal efficiency, Adsorption

Posted Date: September 21st, 2021

DOI: https://doi.org/10.21203/rs.3.rs-915379/v1

License: (c) (1) This work is licensed under a Creative Commons Attribution 4.0 International License.

Read Full License 


\title{
Synthesis and performance evaluation of chitosan/zinc oxide nanocomposite as a highly efficient adsorbent in the removal of reactive red 198 from water
}

Najmeh Amirmahani ${ }^{[\mathrm{a}]}$, Hakimeh Mahdizadeh ${ }^{[\mathrm{b}, \mathrm{c}] *}$, Neda Seyedi ${ }^{[\mathrm{d}] * *}$, Alireza Nasiri $^{[\mathrm{a}]}$, Ghazal Yazdanpanah ${ }^{[\mathrm{a}]}$

${ }^{a}$ Environmental Health Engineering Research Center, Kerman University of Medical Sciences, Kerman, Iran

${ }^{*}$ Department of Environmental Health Engineering, Zarand School of Nursing, Kerman University of Medical Sciences, Kerman, Iran

${ }^{*}$ Student Research Committee, Kerman University of Medical Sciences, Kerman, Iran

${ }^{*}$ Department of Chemistry, Faculty of Science, University of Jiroft, Jiroft, Iran

*First Corresponding author: Hakimeh Mahdizadeh, Department of Environmental Health Engineering, Zarand School of Nursing, Kerman University of Medical Sciences, Kerman, Iran, Tel \& Fax: + (98)3431325435, Post Code: 76169-13555, P. O. Box: 76175-531. Email: H.mahdizadeh2018@gmail.com

**Second Corresponding author: Neda Seyedi, Department of Chemistry, Faculty of Science, University of Jiroft, Jiroft, Iran, Email: nedaseyedi@ujiroft.ac.ir

\begin{abstract}
Disposal of textile industrial effluents causes many environmental problems. The presence of chemical dyes in textile wastewater lead to the primary environmental pollution as well as the production of hazardous secondary compounds that are toxic and carcinogenic. In this study, Chitosan and Chitosan-zinc oxide ( $\mathrm{ZnO})$ nanocomposite were prepared and selected as a low-cost adsorbent with high adsorption capacity for removing reactive red 198 (RR 198) dye from contaminated. After preparation, it was characterized using Fourier-transform infrared spectroscopy [FT-IR], X-ray diffraction spectrophotometer [XRD], and scanning electron microscopy [SEM]. The effect of $\mathrm{pH}$, temperature, time, adsorbent amount, and initial dye concentration were investigated in the removal efficiency of reactive red 198 (RR 198) dyes. The results showed that the maximum adsorption capacity $\left(\mathrm{q}_{\mathrm{m}}\right)$ obtained from the Langmuir equation was $172.41 \mathrm{mg} / \mathrm{g}$ in adsorbent dose of $0.1 \mathrm{~g} / \mathrm{L}, \mathrm{pH}: 4$, temperature of $25^{\circ} \mathrm{C}$, adsorption time of 40 min. The thermodynamic parameters demonstrated the spontaneous and endothermic nature of the adsorption process. Due to the high efficiency of chitosan/ZnO nanocomposite in removal of RR 198 from water and advantages such as high adsorption capacity, simple synthesis, and easy application, it can be used as an effective method in removal of RR 198 from water.
\end{abstract}

Keywords: Chitosan, Chitosan/ZnO nanocomposite, Reactive red 198, High removal efficiency, Adsorption 


\section{Introduction}

Disposal of industrial effluents, including the textile and dyeing industries, causes many environmental problems. In these industries, large amounts of chemicals as well as organic dyes are used during the production process. The effluents of these industries are different from each other in terms of chemical quality and quantity and are one of the biggest sources of pollution (1$3)$. These effluents cause more water pollution and are measured based on the amount of suspended solids, heavy metals, acid, alkali, biological oxygen demand (BOD), and chemical oxygen demand (COD). Most of these chemical and dyes can make primary contamination and also can be converted to dangerous secondary compounds that are toxic and carcinogenic through chemical processes (4,5). Azo dyes include acidic, alkaline, direct, and reactive dyes, which constitute a significant portion of the reactive dyes. These reactive dyes have one or more reactive groups which form covalent bonds with some functional groups (6-8).

Removal of organic dyes from the effluents of textile and dyeing industries is very difficult because of their special chemical structure, and cannot be done with conventional methods of treatment of dye effluents due to inadequate removal efficiency. Combined methods are usually used to treat these effluents $(5,8)$. Numerous physical, chemical, and biological methods are used to decolorize textile effluents that differ in terms of efficiency, economic cost, and environmental effects $(5,7)$. Biological methods are not very efficient for removal of these dyes but oxidation methods are often effective at low concentrations of organic compounds (4,5). However, adsorption of dye molecules by an adsorbent is an effective and cost-effective method. One of the characteristics of a good adsorbent is cost-effectiveness, high adsorption potential, and being environmentally friendly. For this reason, natural adsorbents were used $(7,9)$. Polysaccharides and their derivatives such as chitosan have always been of interest to many researchers $(10,11)$. Chitosan is a natural aminopolysaccharide derived from chitin and its usage as a biosorbent has increased due to its abundance in nature and its low cost compared to commercial adsorbents as well as its excellent chelating behavior (12).

Similar studies have been conducted by different adsorbents to remove a variety of dyes. In a study in India, Dhanapalet al. (2016) investigated the removal of methylene blue, bromophenol blue, and Kumasi brilliant by alpha-chitin nanoparticles (13). In another study in Brazil, Dotto et al. (2015) investigated methylene blue adsorption by the ultrasonic-modified chitin (14). In Turkey, Akkaya et al. (2009) investigated the removal of highly toxic dyes from aqueous solutions by chitin and their synthesized derivatives (15). In Iran, Ramavandi et al. (2014) evaluated the efficiency of shrimp shell in removing methylene blue dye from aqueous solutions (16). In Malaysia, Vakili et al. (2016) investigated the effect of hydrogel chitosan granules in improving the adsorption of reactive blue 4 dye (17). In Egypt, El-Zawahry et al. (2016) conducted a traditional study on the adsorption of reactive black 5 from aqueous solutions using the chitosan/Eichhornia Crassipes composite (18). Owing to these advantages, chitosan has several limitations such as low mechanical strength, extremely high hydrophilicity and poor adsorption capacity (19). To maximize the usage CS, several methods can be applied to modify it, including: modification over 
physical blending, grafting and crosslinking with other polymers, Chemicals or form composites with metal oxide (20-22). $\mathrm{ZnO}$ nanoparticles ( $\mathrm{ZnO} \mathrm{NPs}$ ) is one of the most widely used metal oxides in dye removal treatment due to its biocompatibility, abundant availability and low production cost $(23,24)$. In the present study, the aim is to synthesize $\mathrm{ZnO} /$ chitosan nanocomposite by a facile and economical method. The material was carefully characterized and used for the removal reactive red 198 (RR 198) from water.

\section{Experimental}

\subsection{Materials and Methods}

All materials and solvents were procured from the Merck/Aldrich chemical company and used without further purification. To produce ultrasound waves, an ultrasonic device (HIELSCHERUP400S, Germany) was used. To identify the functional groups in the adsorbent structure, the Fourier-transform infrared spectroscopy (FT-IR, model TENSOR27, Germany) was used. To investigate the deposition of $\mathrm{ZnO}$ particles on chitosan and the crystallinity of chitosan, X-ray diffraction device (XRD, model NPD3000, Italy) was used. Scanning electron microscope (SEM, model 100KV.S411-SEMHITACHI, Japan) was used to study the structure and dimensions of chitosan adsorbent particles and morphology of chitosan/ZnO nanoparticles composite. The dye concentration was determined by UV-VIS spectrophotometer (Germany). Ultraviolet radiation was provided by a 15-watt UV lamp (PHILIPS, the Netherlands). All chemical materials and reagents used were of high purity and provided by Merck company (Germany). Data were analyzed using descriptive statistics by SPSS software version 18.

\subsection{Preparation of Adsorbent (chitosan/ZnO nanocomposite)}

To prepare the chitosan/ZnO nanocomposite, shrimp shells were first prepared from waste and disposable fish shops in the Kerman city and washed with distilled water and sun-dried at ambient temperature. It was then ground for half an hour. The powder was refluxed with 4\% HCL for 36 hours at room temperature to remove organic matter and minerals. At this stage, calcium chloride and minerals were removed. The resulting mixture was then stirred with $50 \% \mathrm{NaOH}$ for $24 \mathrm{~h}$ at $90^{\circ} \mathrm{C}$. At this stage, shrimp shell was deproteinized and degreased. Then, the chitin was extracted from the shrimp shell. For this purpose, the obtained powder in the previous stage was mixed in the ratio of $1 \mathrm{~g}$ of powder to $14 \mathrm{ml}$ of $70 \%$ soda for 72 hours, and the chitin was obtained. In the next step, chitosan should be extracted from chitin. According to literature, more than $50 \%$ of the deacetylated chitin is chitosan. To obtain this percentage of deacetylate, $10 \mathrm{~g}$ of the powder obtained from the previous steps was added to $30 \% \mathrm{NaOH}$ for 48 hours at room temperature to be neutralized, and then, dried. Afterwards, it was exposed to $50 \% \mathrm{NaOH}$ at $70^{\circ} \mathrm{C}$ for $24 \mathrm{~h}$. The next step is the synthesis of chitosan/ $\mathrm{ZnO}$ nanocomposite. To prepare this nanocomposite, first, $\mathrm{ZnO}$ was dissolved in $100 \mathrm{~mL}$ of $0.1 \mathrm{M}$ acetic acid, and then, $1 \mathrm{~g}$ of chitosan was added to this solution. The solution was subjected to ultrasound waves for $30 \mathrm{~min}$. 1M Sodium was then poured into the solution to reach the $\mathrm{pH}$ of the solution to 10 . The solution was stirred continuously for 4 hours at a temperature between 40 and $80^{\circ} \mathrm{C}$. Then, it was placed in the oven at $50^{\circ} \mathrm{C}$ and dried. The powder was then ground for $30 \mathrm{~min}$. 
To prepare the used solutions, reactive red 198 (RR 198) dye with chemical formula $\mathrm{C}_{27} \mathrm{H}_{18} \mathrm{ClN}_{7} \mathrm{Na}_{4} \mathrm{O}_{16} \mathrm{~S}_{5}$ and molecule weight of $984.21 \mathrm{~g} / \mathrm{mol}$ with the maximum adsorption wavelength of $518 \mathrm{~nm}$ was used (Figure 1).

\section{Figure 1.}

\subsection{Adsorption Experiments}

The RR 198 adsorption process on the chitosan and chitosan/ZnO nanocomposite was investigated using aqueous solution of RR 198. Batch experiments were performed by mixing $0.01 \mathrm{~g}$ of the adsorbents with RR 198 solutions $(50 \mathrm{mg} / \mathrm{L})$ in in a glass container $(100 \mathrm{~mL})$. The mixtures were stirred at $200 \mathrm{rpm}$ and then centrifuged at $6000 \mathrm{rpm}$. the samples were collected and filtered, and the adsorption rate of each solution was determined by a spectrophotometer. Factors affecting the adsorption process of RR 198 by chitosan and chitosan/ZnO nanocomposite including $\mathrm{pH}$ (2-10), reaction temperature $\left(25,30,40,50^{\circ} \mathrm{C}\right)$, contact time $(20,40,60,80,100,120 \mathrm{~min})$, amount of adsorbent $(0.1,0.2,0.3,0.4,0.5,0.6 \mathrm{~g})$, and initial dye concentration $(25,50,75,100 \mathrm{mg} / \mathrm{L})$ were considered.

A solution of sodium hydroxide $(0.1 \mathrm{M})$ and hydrochloric acid $(0.1 \mathrm{M})$ was used to adjust the $\mathrm{pH}$. by sampling at a specific time. The amount of dye adsorbed at equilibrium time was determined using Eq. (1) $(25,26)$.

$$
q_{e}=\frac{\left(c_{0}-c_{t}\right) v}{m}
$$

In order to determine the reaction adsorption isotherm, after determining the dye removal values under different conditions, the obtained data were analyzed by the Langmuir, Freundlich models. The linear equations of the Langmuir and Freundlich isotherms are presented in Eqs. (2 and 3) (25).

$$
\begin{aligned}
& \frac{C_{e}}{q_{e}}=\frac{1}{K_{L} q_{m}}+\frac{C_{e}}{q_{m}} \\
& \log q_{e}=\log k_{f}+\frac{1}{n} \log C_{e}
\end{aligned}
$$

Where $\mathrm{q}_{\mathrm{e}}$ is the amount of contaminant adsorbed on the adsorbent at equilibrium $(\mathrm{mg} / \mathrm{g}), \mathrm{C}_{\mathrm{e}}$ is the equilibrium concentration of contaminants in solution $(\mathrm{mg} / \mathrm{L}), \mathrm{q}_{\mathrm{m}}$ is the maximum adsorption capacity $(\mathrm{mg} / \mathrm{g}), \mathrm{K}_{\mathrm{L}}$ is the Langmuir equilibrium constant $(1 / \mathrm{mg}), \mathrm{C}_{0}$ is the initial concentration of contaminant in solution $(\mathrm{mg} / \mathrm{L}), \mathrm{V}$ is the solution volume $(\mathrm{L}), \mathrm{M}$ is the mass of dried adsorbent added to bottles $(\mathrm{g}), \mathrm{k}_{\mathrm{f}}$ is the adsorption capacity in unit concentration $\left.\left.[(\mathrm{mg} / \mathrm{g})(1 / \mathrm{mg})]\right)\right]$ and $\frac{1}{n}$ is the intensity of surface adsorption, which indicates the type of isotherm $\left(\frac{1}{n}=0\right.$ is irreversible, $\frac{1}{n}>$ 1 is undesirable, $0<\frac{1}{n}<1$ is desirable) (25). 
The thermodynamic parameters including equilibrium constant $\left(\mathrm{K}^{0}\right)$, standard enthalpy changes $\left(\Delta \mathrm{H}^{0}\right)$ and standard free energy changes $\left(\Delta \mathrm{G}^{0}\right)$ were considered by Eqs (4-6) (27).

$\Delta G=-R T \ln K_{d}$

$\ln k_{d}=\frac{\Delta S}{R}-\frac{\Delta H}{R T}$

$k_{d}=\frac{q_{e}}{C_{e}}$

Where $R$ exhibits the gas constant $\left(8.314 \mathrm{~J} \cdot \mathrm{mol}^{-1} \cdot \mathrm{K}^{-1}\right), k_{d}$ exhibits the thermodynamic equilibrium constant, and $T(\mathrm{~K})$ represents the absolute temperature(27).

\section{Results and Discussion}

\subsection{Characterization of chitosan/ZnO nanoparticles composite}

\subsubsection{FT-IR spectroscopy}

Infrared spectroscopy test was used to investigate the structural changes and identify the adsorbents (Figures 1). Figure 2 shows the FT-IR spectrum of shrimp shell (2a), chitin spectrum (2b), chitosan (2c), CS/n- ZnO nanocomposite (2d).

\section{Figure 2.}

Fig.2(a) indicating the amine group stretching at $1658.49 \mathrm{~cm}^{-1}$ and $\mathrm{OH}$ group stretching at 3435.07 and $3283.99 \mathrm{~cm}^{-1}$. C-O group stretching was also observed in absorption bands at 1072.20 and $1029.83 \mathrm{~cm}^{-1}$. Fig.2(b) shows the chitin spectrum, and the absorption bands at 1558.59 to 1626.76 $\mathrm{cm}^{-1}$ are related to the amine group. Absorption bands due to $\mathrm{OH}$ stretching are seen at 3447.30 $\mathrm{cm}^{-1}$, and irregular bands at 102672 to $1157.63 \mathrm{~cm}^{-1}$ are related to the carboxylic acid O-H stretch. Fig. 2 (c) shows the FT-IR spectrum of chitosan, indicating that the adsorption band at 1658.75 $\mathrm{cm}^{-1}$ belongs to the carbonyl group and at $1594.22 \mathrm{~cm}^{-1}$ belongs to the amide group, and the absorption bands at 1034.96 to $1153.28 \mathrm{~cm}^{-1}$ belongs to the carboxylic acid stretch. The absorption band at $2885.15 \mathrm{~cm}^{-1}$ is related to the bending vibration of $\mathrm{CH}$. And the absorption band at 3444.15 $\mathrm{cm}^{-1}$ is due to the stretching of the OH group. Fig. 2 (d) shows the FT-IR spectrum of CS/n-ZnO nanocomposite. The bending vibration of the primary amine appears as a wide band at 1415.92 to $1650.19 \mathrm{~cm}^{-1}$. The bending vibration of C-O appeared at $1076.24 \mathrm{~cm}^{-1}$. And the absorption band at $3430.86 \mathrm{~cm}^{-1}$ belongs to the hydroxyl group.

\subsubsection{X-ray diffraction test (XRD)}

X-ray diffraction test is used to evaluate the crystallinity of chitosan. Figure (3) shows the XRD diagram of the chitosan and $\mathrm{CS} / \mathrm{n}-\mathrm{ZnO}$ nanocomposite. 
The crystallinity index of chitosan (crI) is obtained from Eq. (1), which has an effect on the removal rate.

$$
c r I=\left(I a I_{110}\right) r I_{a}
$$

Where $\mathrm{I}_{110}$ is the peak intensity ratio and $\mathrm{I}_{\mathrm{a}}$ is the dispersion related to the study area. Using this equation, $2 \mathrm{~A}=16 \%$ crystallinity was obtained to be $72 \%$. Peaks at $2 \mathrm{~A}$ values of $31.9,34.5,36.4$, 47.6, 56.7, and $62.9^{\circ}$ are associated with Zno crystal plates. These results successfully show the hexagonal structure of $\mathrm{ZnO}$ on CS (2b).

Figure 3.

\subsubsection{Scanning electron microscope (SEM) results}

Electron microscopy is a very suitable tool for identifying the morphology of the adsorbent surface and examining its physical properties, as well as determining the shape of particles, size, and distribution of cavities. The SEM image of the polymer adsorbent (chitosan) is shown in Figure 4 (a).

SEM images of the $\mathrm{CS} / \mathrm{n}-\mathrm{ZnO}$ composite show $\mathrm{ZnO}$ on CS. They also show that these adsorbents have a porous structure, which is one of the reasons for their decolorization ability. The results are shown in Figure 4 (b).

\section{Figure 4.}

\subsection{Investigation of adsorption behaviors of reactive red 198 at different conditions}

The adsorption behavior of the dye on chitosan and chitosan- $\mathrm{ZnO}$ nanoparticles was investigated under different conditions.

\subsubsection{Investigation of the effect of $\mathrm{pH}$ on the dye adsorption process}

The highest amount of dye adsorption was obtained under acidic conditions and the optimum $\mathrm{pH}$ of 4. The results are shown in Figure 5.

\section{Figure 5.}

The $\mathrm{pH}$ of the solution plays an important role in the adsorption process and adsorption capacity. The adsorption capacity increases with decreasing $\mathrm{pH}$. At acidic $\mathrm{pH}$, there is a high and significant electrostatic intraction between the positively charged surface of adsorbents and negatively charged anionic dye molecules. As the $\mathrm{pH}$ decreases, the number of positively charged sites increases. Positively charged sites tend to adsorb anionic dyes due to their electrostatic attraction. However, in extremely acidic conditions, adsorption is likely to decrease due to chitosan depolymerization. And with increasing $\mathrm{pH}$, the adsorbent surface becomes more negative, which is due to the electrostatic repulsion between the adsorbent and the adsorbent, and consequently, the amount of adsorption decreases (28). A study by Gulnaz et al. (2011) in Turkey on the removal 
of reactive 198 dye by Potamogeton crispus also showed that the dye removal efficiency increased by reducing $\mathrm{pH}$ from 5 to 1 (29). In another study conducted by Bazrafshan et al. (2012) in Iran, it was confirmed that the highest adsorption rate of reactive 198 dye by pistachio-nut shell ash occurs under acidic conditions ( $\mathrm{pH}: 2$ ), which is consistent with the results of the present study (30). Dutta et al. (2009) reported that the adsorption percentage of $\mathrm{RR} 198$ dye by $\mathrm{TiO}_{2}$ nanoparticles decreases with increasing $\mathrm{pH}$ from 3 to 7 and the dye adsorption capacity is higher under acidic conditions (31).

\subsubsection{Investigation of the effect of temperature on the dye adsorption process}

Figure 6 shows the results of the effect of temperature between 25 and $50^{\circ} \mathrm{C}$ on surface adsorption process of RR 198 dye.

\section{Figure 6.}

The study of the effect of temperature on the adsorption process shows that with increasing temperature, the adsorption rate increases slightly. This can be explained by the Arrhenius equation, according to which by increasing energy, the mobility of molecules and the effective collisions between adsorbed molecules and the adsorbent surface increases, indicating that the reaction is endothermic (32). Since the increase of efficiency was not significant, so in order to facilitate the experiments, the temperature of $25^{\circ} \mathrm{C}$, which was in the range of ambient temperature, was selected as the optimal temperature. In a study by Asgari et al. (2020) in Iran, the adsorbtion of metronidazole by $\mathrm{Fe}_{3} \mathrm{O}_{4}$-chitosan, the adsorption efficiency increased with increasing temperature, which confirm the endothermic nature of the adsorption (33). In a study conducted by Sohni et al. (2019) in Malaysia on the adsorption of methylene blue dye by chitosan/nanolignin-based composite, it was revealed that the dye adsorption rate increased with increasing temperature, indicating that the dye adsorption process is endothermic (22).

\subsubsection{Evaluation of the effect of contact time on the dye adsorption process}

the relationship between removal efficiency of RR 198 dye and adsorption timewere investigated, the results are shown in Figure 7. The results indicate that the removal of a significant amount of dye occurs within the first 40 minutes of the process, and then, reaches a constant value. In adsorption processes, with increasing time due to adsorption of the adsorbent with the analyte, the active sites of the adsorbent are occupied until a balance is established between the molecules or ions in the solution and the adsorbent surface, and increasing the contact time does not increase the adsorption more. At this time, the adsorbent is saturated and needs to be regenerated or replaced, which is consistent with the results of other studies (10-18). The adsorption equilibrium time for this adsorbent is 40 minutes.

Figure 7. 


\subsubsection{Effect of adsorbent amount on adsorption process}

Determining the optimal amount of adsorbent is a very important factor, because it determines the amount of decolorization. The percentage of dye removed to different amounts of adsorbent for the removal of RR 198 dye is shown in Figure 8. The results show that at different amounts of adsorbent with different masses $(0.1,0.03,4.3,0.05,0.6 \mathrm{~g})$, the optimal amount for both adsorbents is $0.01 \mathrm{~g}$.

\section{Figure 8.}

With increasing the amount of adsorbent, the removal efficiency increases, which is due to the increase of the level of adsorbent and accessibility to more adsorption sites. As the adsorbent particles purify a certain volume of liquid, increasing the amount of adsorbent accelerates the equilibrium between adsorbant and adsorbed because the number of particles that purify the same volume of liquid increases (34). In a study by Asgari et al. (2020) in Iran, for the adsorption of metronidazole by $\mathrm{Fe}_{3} \mathrm{O}_{4}$-chitosan, the adsorption capacity was reduced by increasing the adsorbent dose from $0.1-2 \mathrm{~g} / \mathrm{L}$. They reported that the decrease in adsorption capacity with increasing adsorbent dose is due to the unsaturation of the active adsorption sites on the adsorbent surface, which is consistent with the results of the present study (33).

\subsubsection{The effect of initial dye concentration on the adsorption process}

Figure 9 shows the effect of initial dye concentration on the removal efficiency. The optimum initial dye concentration for adsorbent was $50 \mathrm{mg} / \mathrm{L}$.

\section{Figure 9.}

At low initial concentrations, the dye adsorption by the adsorbent is very high and reach equilibrium rapidly. This determines the probability of forming a monolayer coating of molecules on the outer surface of the adsorbent. At a constant amount of adsorbents, as the concentration of the solution increases, the amount of adsorbed substance increases and the percentage of adsorption decreases. In other words, the residual concentration of dye molecules to the available sites of adsorption is low, so some parts of the adsorption will be independent of the initial concentration (35). In a study by Asgari et al. (2020) in Iran, for the adsorption of metronidazole by $\mathrm{Fe}_{3} \mathrm{O}_{4}$-chitosan, the adsorption efficiency decreased by increasing the initial concentration of metronidazole from 10 to $100 \mathrm{mg} / \mathrm{L} \mathrm{(33).}$

\subsection{Evaluation of equilibrium isotherms (Langmuir and Freundlich)}

The constant coefficients and correlation coefficients of the Freundlich and Langmuir adsorption isotherms for the adsorption of reactive red 198 (RR 198) dye on the adsorbent are shown in Table 1 .

Adsorption of RR 198 with both chitosan adsorbent and chitosan-ZnO nanocomposite followed the Langmuir isotherm model well. Data were analyzed to select the best isotherm by the linear 
regression analysis of these models and comparing the correlation coefficient $\left(\mathrm{R}^{2}\right)$. The correlation coefficient of Langmuir isotherm was higher than Freundlich isotherm. The Langmuir isotherm is based on the monolayer adsorption of molecules or ions on the adsorbent surface, and the adsorption energy is the same on the molecular surface. However, in the Freundlich isotherm, adsorption occurs in several layers and the adsorption energy is different at different levels. In a study conducted by Sohni et al. (2019) in Malaysia, the adsorption of methylene blue dye by chitosan/nano-lignin-based composite followed the Langmuir model, which confirmed the monolayer adsorption of dye on the adsorbent surface. The $\mathrm{q}_{\mathrm{m}}$ obtained from the Langmuir equation was $74.07 \mathrm{mg} / \mathrm{g}$, which is much lower than the $\mathrm{q}_{\mathrm{m}}$ obtained in the present study. Therefore, the adsorbent synthesized with natural organic materials showed a high adsorption capacity.

The $\mathrm{K}_{\mathrm{L}}$ constant was obtained from Langmuir diagram, which shows the amount of $\mathrm{q}_{\mathrm{m}}$ adsorption energy, which is the maximum adsorption capacity of the adsorbent. Freundlich equations constants such as n were obtained from diagram.

\section{Table 1.}

\subsection{Evaluation of Adsorption Thermodynamics}

Thermodynamics data (Gibbs energy $\left(\Delta \mathrm{G}^{0}\right)$, enthalpy $\left(\Delta \mathrm{H}^{0}\right)$, and entropy $\left(\Delta \mathrm{S}^{0}\right)$ ) related to the effect of temperature on $\mathrm{R}$ at various temperatures $(318 \mathrm{~K}, 328 \mathrm{~K}, 338 \mathrm{~K}$ and $348 \mathrm{~K}$ ) were calculated under the optimized obtained conditions. From the plot of $\ln \mathrm{K}^{\mathrm{o}}$ versus $1 / \mathrm{T}$ (Fig. 10), the thermodynamic parameters for the adsorption process were calculated and the results are reported in Table 2 .

\section{Table 2.}

Fig. 10.

It can be mentioned that the $\Delta \mathrm{H}^{\circ}$ values is positive (Table 2), confirming an endothermic adsorption and also, $\Delta \mathrm{H}^{\circ}$ values for $\mathrm{CS}$ and $\mathrm{CS} / \mathrm{nZnO}$ adsorbents are higher than $20.9 \mathrm{~kJ} / \mathrm{mol}$, which approves the chemisorption process (36). The positive value of $\Delta \mathrm{S}^{\circ}$ reflected decreasing the randomness decreased due to occurrence of the adsorption process (37).

As seen, the value of $\Delta \mathrm{G}^{\circ}$ is negative, indicating a spontaneous adsorption process.Additional, the less value of $\Delta \mathrm{G}^{\circ}$ at the higher temperatures indicates undesirability of the adsorption process at the elevated temperature (38).

\section{Conclusion}

In this study, $\mathrm{CS}$ and $\mathrm{CS} / \mathrm{ZnO}$ nanocomposite were prepared as a cost-effective adsorbent by natural organic materials (shrimp shell) in an easy method and was used to remove reactive red 198 (RR 198) dye from contaminated water in a discontinuous system. Evaluation of the functional 
groups on the surface of chitosan using FT-IR showed that the surface of CS has different functional groups such as hydroxyl, amine, and carbonyl groups. SEM images showed that chitosan has a relatively porous structure, which is one of the reasons for the removal of the dye of this polymer. Evaluation of effective variables in removing dye showed that the amount of decolorization increases at acidic $\mathrm{pH}$ values due to high electrostatic attraction between the positively charged adsorbents and negatively charged anionic dye molecules. The maximum amount of dye removal on adsorbents occurred in the first 40 minutes. The study of the effect of temperature on this process showed that with increasing temperature, the amount of dye adsorption increases. With increasing the amount of adsorbent, the removal efficiency increased. Also, with increasing the initial dye concentration, the percentage of dye removal decreased. The maximum dye removal efficiency was more than $99 \%$ for $\mathrm{CS}$ adsorbent and $99.50 \%$ for $\mathrm{ZnO}$ nanocomposite adsorbent. The isotherm result showed that for both adsorbents, it follows the Langmuir isotherm as a dye monolayer adsorption. The analysis of thermodynamic parameters exhibited the exothermic and spontaneous nature of adsorption process at various temperatures. The $\mathrm{q}_{\mathrm{m}}$ value obtained from the Langmuir equation was $172.41 \mathrm{mg} / \mathrm{g}$, which confirms that chitosan synthesized with the basis of natural organic matter has a high adsorption capacity and can be proposed as a surface adsorbent in the water and wastewater treatment industry.

\section{Acknowledgments}

This research resulted from the proposal with the ethic approval code of IR.KMU.REC.1395.646. and Reg. No. 95000475, conducted at the Environmental Health Engineering Research Center and was sponsored by the Vice-Chancellor for Research and Technology of Kerman University of Medical Sciences. A note of appreciation is expressed here to the Vice-Chancellor and to all university staff who provided assistance to make this study possible.

\section{Reference}

1. Mahdizadeh H, Nasiri A, Gharaghani MA, Yazdanpanah G. Hybrid UV/COP advanced oxidation process using $\mathrm{ZnO}$ as a catalyst immobilized on a stone surface for degradation of acid red 18 dye. MethodsX. 2020;7:101118.

2. Nasiri A, Malakootian M, Heidari MR, Asadzadeh SN. $\mathrm{CoFe}_{2} \mathrm{O}_{4} @$ Methylcelloluse as a New Magnetic Nano Biocomposite for Sonocatalytic Degradation of Reactive Blue 19. J Polym Environ. 2021;1-16.

3. Malakootian M, Nasiri A, Alibeigi AN, Mahdizadeh H, Gharaghani MA. Synthesis and stabilization of $\mathrm{ZnO}$ nanoparticles on a glass plate to study the removal efficiency of acid red 18 by hybrid advanced oxidation process (Ultraviolet/ZnO/ultrasonic). 2019;

4. Malakootian M, Smith Jr A, Gharaghani MA, Mahdizadeh H, Nasiri A, Yazdanpanah G. Decoloration of textile Acid Red 18 dye by hybrid UV/COP advanced oxidation process using $\mathrm{ZnO}$ as a catalyst immobilized on a stone surface. Desalin WATER Treat. 2020;182:385-94.

5. Mahdizadeh H, Nasiri A, Gharaghani MA, Yazdanpanah G. Hybrid UV/COP advanced oxidation process using $\mathrm{ZnO}$ as a catalyst immobilized on a stone surface for degradation of acid red 18 dye. MethodsX. 2020;7:101118.

6. Arshad R, Bokhari TH, Javed T, Bhatti IA, Rasheed S, Iqbal M, et al. Degradation product 
distribution of Reactive Red-147 dye treated by UV/H2O2/TiO2 advanced oxidation process. J Mater Res Technol [Internet]. 2020;9(3):3168-78. Available from: https://www.sciencedirect.com/science/article/pii/S2238785419319635

7. Mehdinejad MH, Mengelizadeh N, Bay A, Pourzamani H, Hajizadeh Y, Niknam N, et al. Adsorption of methylene blue from aqueous solutions by cellulose and nanofiber cellulose and its electrochemical regeneration. Desalin Water Treat. 2018;110:250-63.

8. Malakootian M, Mahdizadeh H, Khavari M, Nasiri A, Gharaghani MA, Khatami M, et al. Efficiency of novel $\mathrm{Fe} / \mathrm{charcoal} /$ ultrasonic micro-electrolysis strategy in the removal of Acid Red 18 from aqueous solutions. J Environ Chem Eng. 2020 Apr 1;8(2).

9. Sadeghi S, Raki G, Amini A, Mengelizadeh N, Amin MM, Hashemi M. Study of the effectiveness of the third generation polyamideamine and polypropylene imine dendrimers in removal of reactive blue 19 dye from aqueous solutions. Environ Heal Eng Manag J. 2018;5(4):197-203.

10. Kyzas GZ, Bikiaris DN, Lazaridis NK. Low-swelling chitosan derivatives as biosorbents for basic dyes. Langmuir. 2008;24(9):4791-9.

11. Wong YC, Szeto YS, Cheung WH, McKay G. Equilibrium studies for acid dye adsorption onto chitosan. Langmuir. 2003;19(19):7888-94.

12. Rinaudo M. Chitin and chitosan: Properties and applications. Prog Polym Sci. 2006;31(7):603-32.

13. Dhanapal V, Subramanian K. Modified chitosan for the collection of reactive blue 4, arsenic and mercury from aqueous media. Carbohydr Polym. 2015;117:123-32.

14. Dotto GL, Santos JMN, Rodrigues IL, Rosa R, Pavan FA, Lima EC. Adsorption of methylene blue by ultrasonic surface modified chitin. J Colloid Interface Sci. 2015;446:133-40.

15. Akkaya G, Uzun İ, Güzel F. Adsorption of some highly toxic dyestuffs from aqueous solution by chitin and its synthesized derivatives. Desalination. 2009;249(3):1115-23.

16. Ramavandi B, Leili M. Efficiency of shrimp shell to remove methylene blue from aqueous solutions. J Heal. 2015;5(4):310-25.

17. Vakili M, Rafatullah M, Ibrahim MH, Abdullah AZ, Salamatinia B, Gholami Z. Chitosan hydrogel beads impregnated with hexadecylamine for improved reactive blue 4 adsorption. Carbohydr Polym. 2016;137:139-46.

18. El-Zawahry MM, Abdelghaffar F, Abdelghaffar RA, Hassabo AG. Equilibrium and kinetic models on the adsorption of Reactive Black 5 from aqueous solution using Eichhornia crassipes/chitosan composite. Carbohydr Polym. 2016;136:507-15.

19. Vakili M, Rafatullah M, Salamatinia B, Abdullah AZ, Ibrahim MH, Tan KB, et al. Application of chitosan and its derivatives as adsorbents for dye removal from water and wastewater: A review. Carbohydr Polym [Internet]. 2014;113:115-30. Available from: https://www.scopus.com/inward/record.uri?eid=2-s2.0-

84904983883\&doi=10.1016\%2Fj.carbpol.2014.07.007\&partnerID=40\&md5=e9385e9075 9221e289038a86fbb548fd

20. Negm NA, Hefni HHH, Abd-Elaal AAA, Badr EA, Abou Kana MTH. Advancement on modification of chitosan biopolymer and its potential applications. Int J Biol Macromol [Internet]. 2020;152:681-702. Available from: https://www.sciencedirect.com/science/article/pii/S0141813020304190

21. Kamoun EA, Chen X, Mohy Eldin MS, Kenawy E-RS. Crosslinked poly(vinyl alcohol) hydrogels for wound dressing applications: A review of remarkably blended polymers. Arab 
J Chem [Internet]. 2015;8(1):1-14. Available from: https://www.sciencedirect.com/science/article/pii/S1878535214001403

22. Sohni S, Hashim R, Nidaullah H, Lamaming J, Sulaiman O. Chitosan/nano-lignin based composite as a new sorbent for enhanced removal of dye pollution from aqueous solutions. Int J Biol Macromol [Internet]. 2019;132:1304-17. Available from: https://www.sciencedirect.com/science/article/pii/S0141813019306671

23. Amirmahani N, Mahdizadeh H, Malakootian M, Pardakhty A, Mahmoodi NO. Evaluating Nanoparticles Decorated on Fe3O4@SiO2-Schiff Base (Fe3O4@SiO2-APTMS-HBA) in Adsorption of Ciprofloxacin from Aqueous Environments. J Inorg Organomet Polym Mater [Internet]. 2020;30(9):3540-51. Available from: https://www.scopus.com/inward/record.uri?eid=2-s2.0$85082055595 \&$ doi $=10.1007 \% 2$ Fs 10904-020-01499$5 \&$ partnerID $=40 \& \mathrm{md} 5=03 \mathrm{db} 18 \mathrm{bd} 68646622 \mathrm{de} 41 \mathrm{~b} 60 \mathrm{c} 97 \mathrm{c} 23 \mathrm{a} 4 \mathrm{~d}$

24. Malakootian M, Gharaghani MA, Dehdarirad A, Khatami M, Ahmadian M, Heidari MR, et al. $\mathrm{ZnO}$ nanoparticles immobilized on the surface of stones to study the removal efficiency of 4-nitroaniline by the hybrid advanced oxidation process (UV/ZnO/O3). J Mol Struct. 2019 Jan 15;1176:766-76.

25. Mahdizadeh H, Malakootian M. Optimization of ciprofloxacin removal from aqueous solutions by a novel semi-fluid Fe/charcoal micro-electrolysis reactor using response surface methodology. Process Saf Environ Prot. 2019;123:299-308.

26. Amirmahani N, Mahmoodi NO, Malakootian M, Pardakhty A, Mahdizadeh H. Adsorption of 4-chlorophenol from aqueous solutions with nanoparticles decorated on Fe3O4@SiO2APTMS-SALAL as an efficient magnetically recoverable nanocomposite. Desalin WATER Treat. 2021;223:188-99.

27. Jawhid O, Seyedi N, Zohuri GH, Ramezanian N. Cellulose Schiff Base as a Bio-based Polymer Ligand: Extraction, Modification and Metal Adsorption Study. J Polym Environ. 2021;29(6):1860-8.

28. Salehi R, Arami M, Mahmoodi NM, Bahrami H, Khorramfar S. Novel biocompatible composite (chitosan-zinc oxide nanoparticle): preparation, characterization and dye adsorption properties. Colloids Surfaces B Biointerfaces. 2010;80(1):86-93.

29. Gulnaz O, Sahmurova A, Kama S. Removal of Reactive Red 198 from aqueous solution by Potamogeton crispus. Chem Eng J. 2011;174(2-3):579-85.

30. Bazrafshan E, Kord Mostafapour F, Barikbin B. Decolorization of Reactive Red 198 by means ofpistachio-nut shell ash. J Birjand Univ Med Sci. 2012;19(3):266-76.

31. Dutta S, Parsons SA, Bhattacharjee C, Jarvis P, Datta S, Bandyopadhyay S. Kinetic study of adsorption and photo-decolorization of Reactive Red 198 on $\mathrm{TiO}_{2}$ surface. Chem Eng J. 2009;155(3):674-9.

32. Zhu H, Jiang R, Fu Y, Guan Y, Yao J, Xiao L, et al. Effective photocatalytic decolorization of methyl orange utilizing $\mathrm{TiO}_{2} / \mathrm{ZnO} /$ chitosan nanocomposite films under simulated solar irradiation. Desalination. 2012;286:41-8.

33. Asgari E, Sheikhmohammadi A, Yeganeh J. Application of the $\mathrm{Fe}_{3} \mathrm{O}_{4}$-chitosan nanoadsorbent for the adsorption of metronidazole from wastewater: Optimization, kinetic, thermodynamic and equilibrium studies. Int J Biol Macromol [Internet]. 2020;164:694-706. Available from: https://www.sciencedirect.com/science/article/pii/S0141813020339477

34. Chatterjee S, Chatterjee S, Chatterjee BP, Das AR, Guha AK. Adsorption of a model anionic dye, eosin Y, from aqueous solution by chitosan hydrobeads. J Colloid Interface Sci. 
2005;288(1):30-5.

35. Mahmoodi NM, Arami M. Modeling and sensitivity analysis of dyes adsorption onto natural adsorbent from colored textile wastewater. J Appl Polym Sci. 2008;109(6):4043-8.

36. Zahedifar M, Seyedi N, Shafiei S, Basij M. Surface-modified magnetic biochar: Highly efficient adsorbents for removal of Pb (II) and Cd (II). Mater Chem Phys. 2021;271:124860.

37. Haffad H, Zbair M, Anfar Z, Ahsaine HA, Bouhlal H, Khallok H. Removal of reactive red198 dye using chitosan as an adsorbent: optimization by central composite design coupled with response surface methodology. Toxin Rev. 2019;

38. Subramani SE, Thinakaran N. Isotherm, kinetic and thermodynamic studies on the adsorption behaviour of textile dyes onto chitosan. Process Saf Environ Prot. 2017;106:110. 
Figures

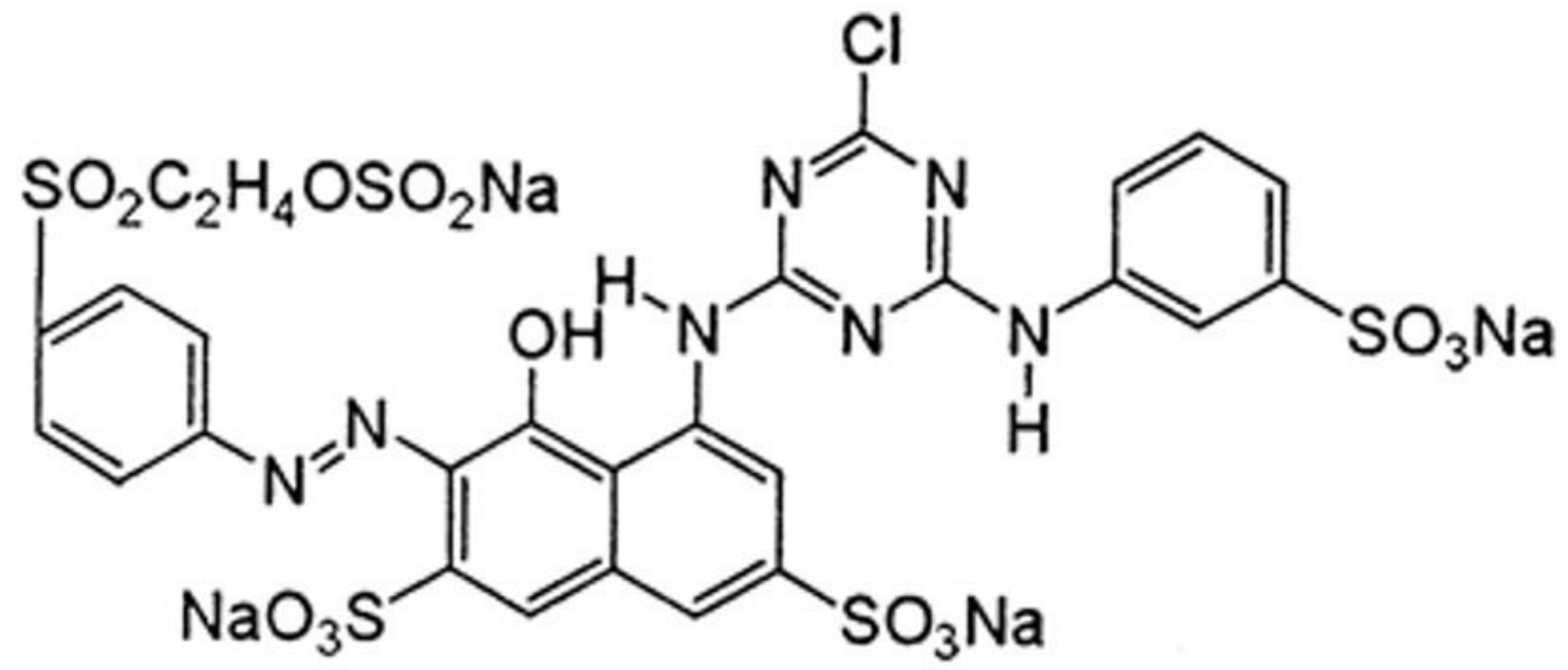

Figure 1

Molecular structure of reactive red 198 (RR 198) dye. 


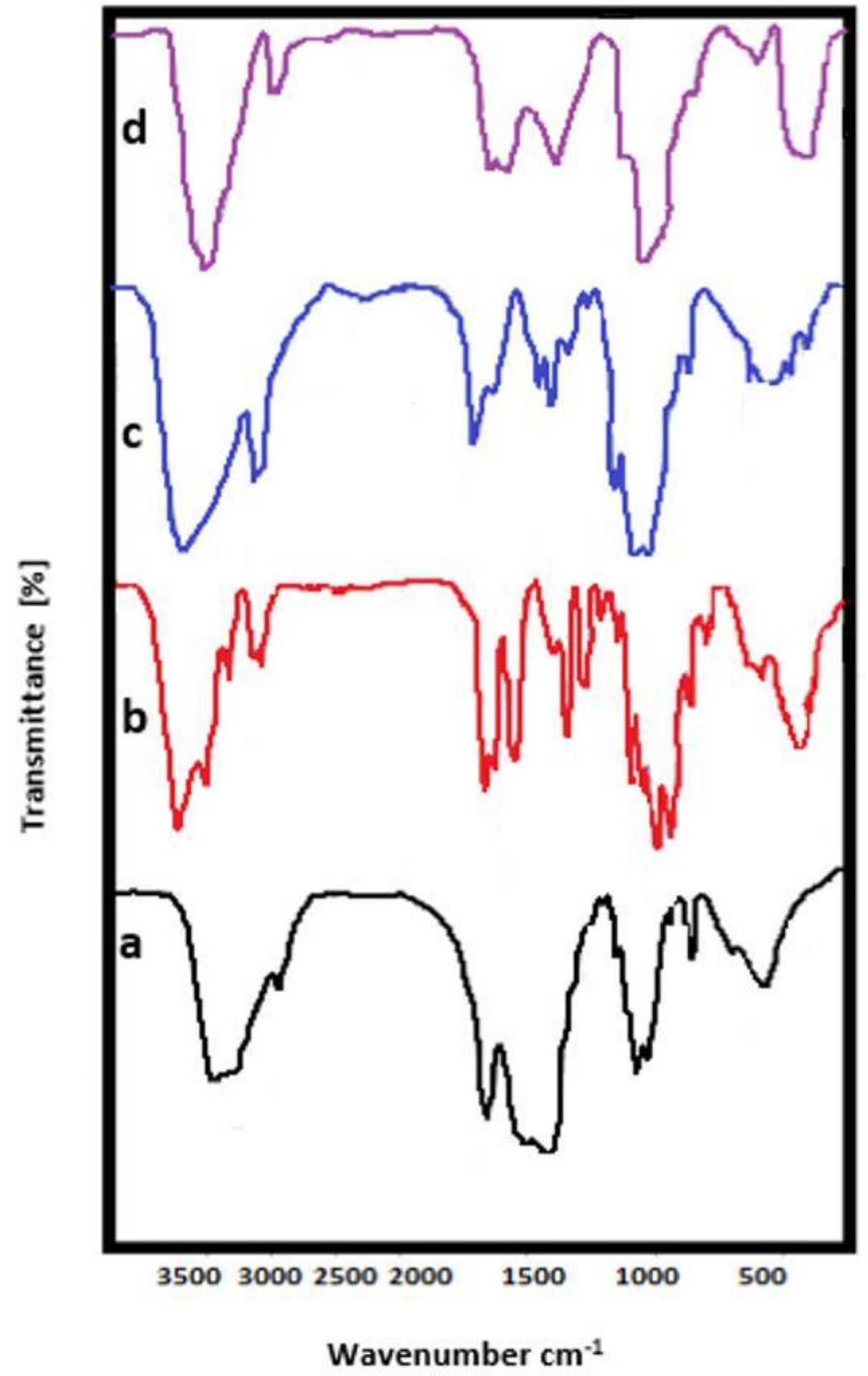

Figure 2

FT-IR spectrum of shrimp shell (a), chitin (b), chitosan (c), and CS/n-ZnO (d). 

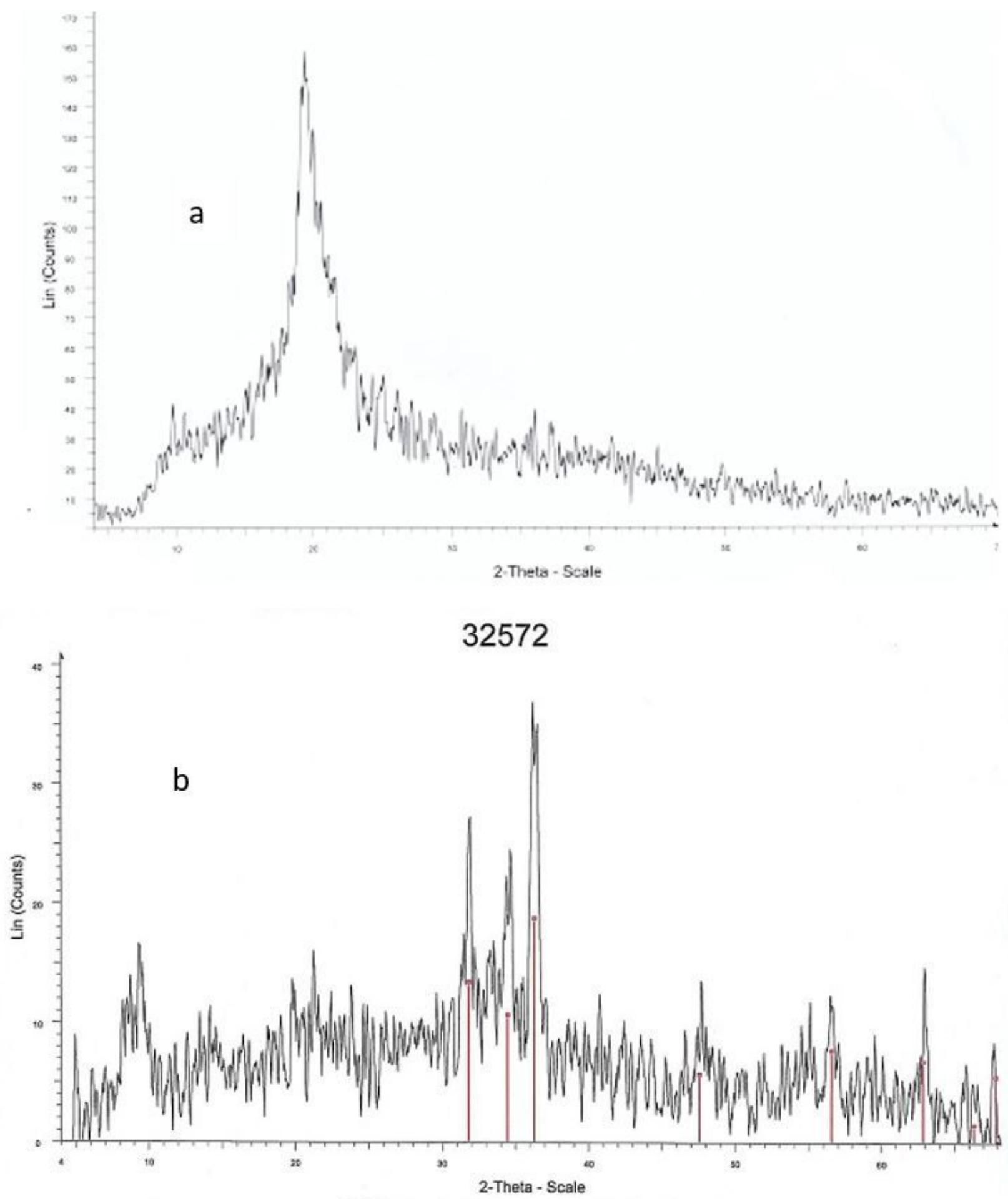

Figure 3

XRD pattern of the chitosan (a), and CS/n-ZnO. 

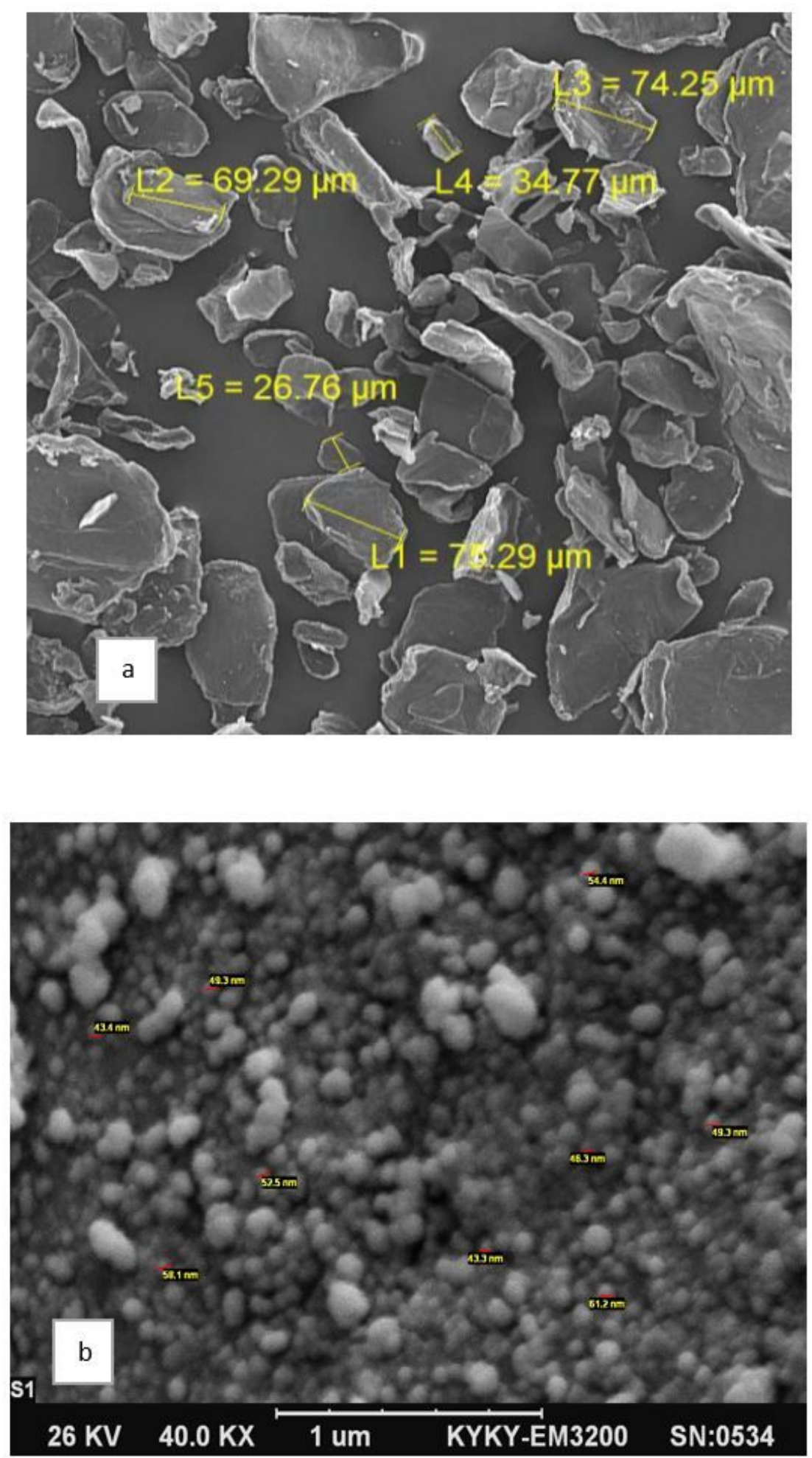

\section{Figure 4}

SEM image of chitosan (a), and nanocomposite (CS/n-ZnO) (b). 


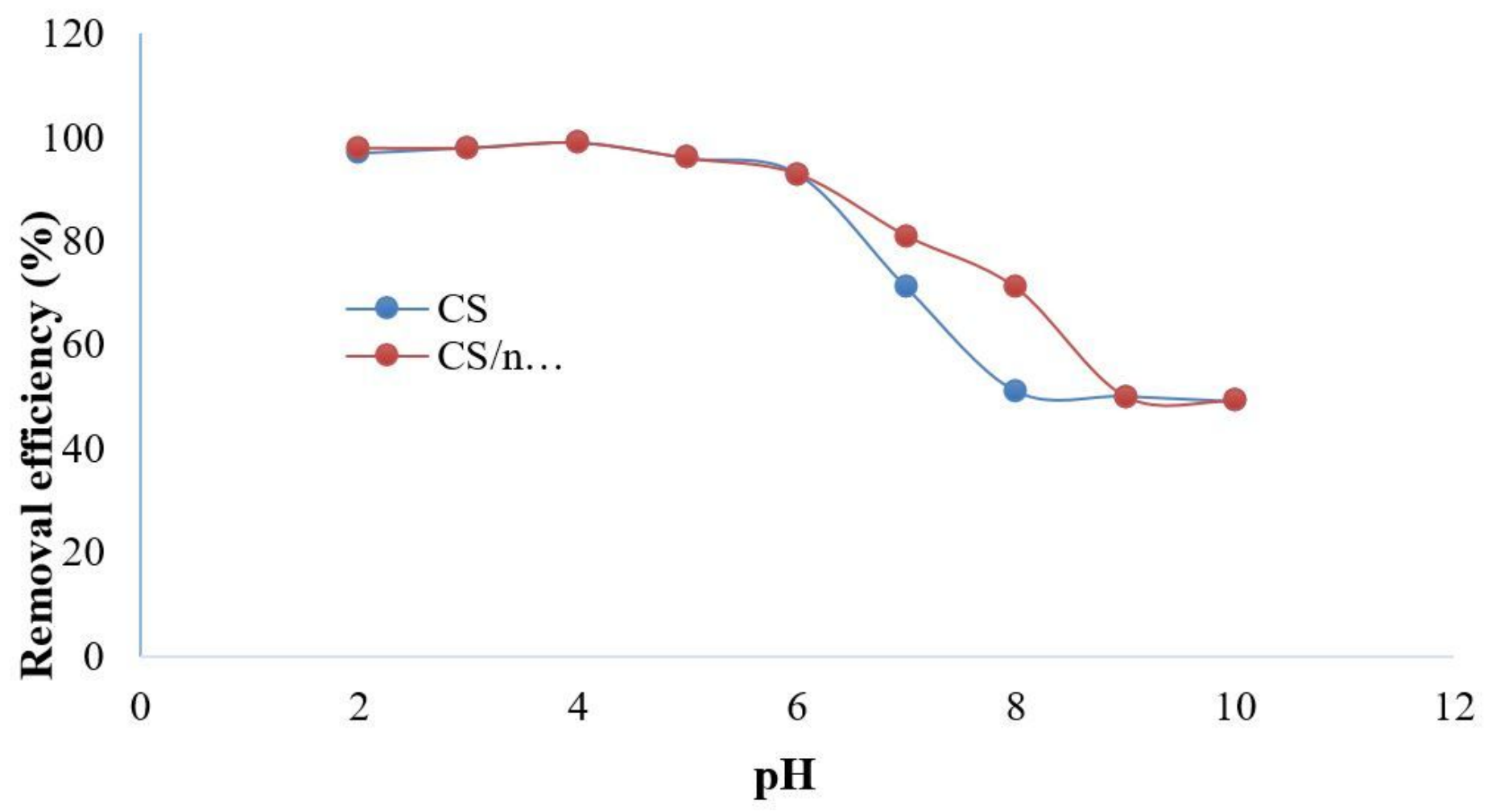

Figure 5

Effect of $\mathrm{pH}$ on the adsorption process under specific conditions (solution volume: $100 \mathrm{~mL}$, adsorbent mass: $0.01 \mathrm{~g}$, initial dye concentration: $50 \mathrm{mg} / \mathrm{L}$, temperature: $25^{\circ} \mathrm{C}$, time: $40 \mathrm{~min}$, and stirrer speed: 200 rpm). 


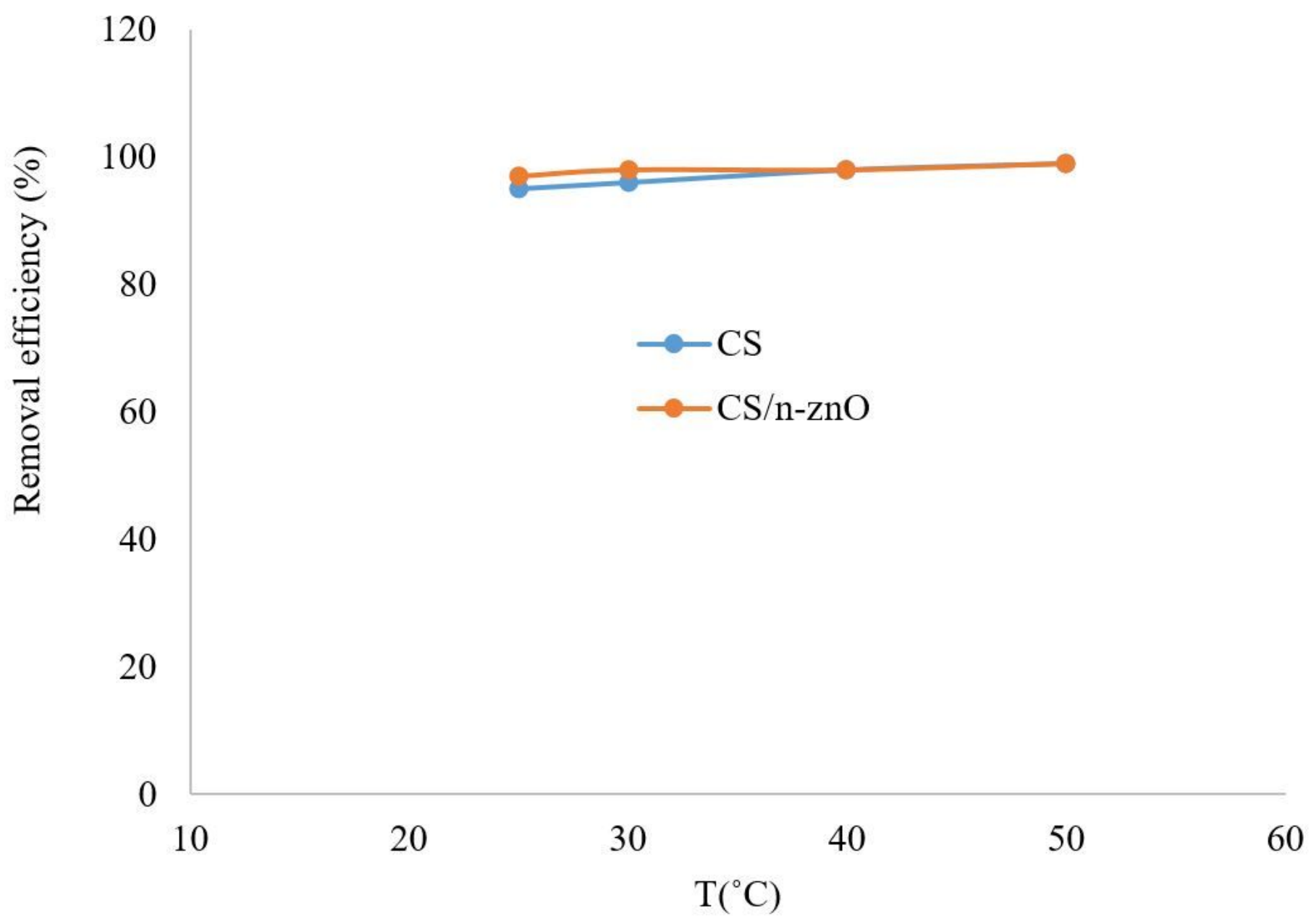

Figure 6

Effect of temperature on the surface adsorption process of RR 198 dye under specific conditions (solution volume: $100 \mathrm{~mL}$, adsorbent mass: $0.01 \mathrm{~g}$, initial concentration of dye: $50 \mathrm{mg} / \mathrm{L}$ ), pH: 4, time: 40 min, and stirrer speed: 200 rpm). 


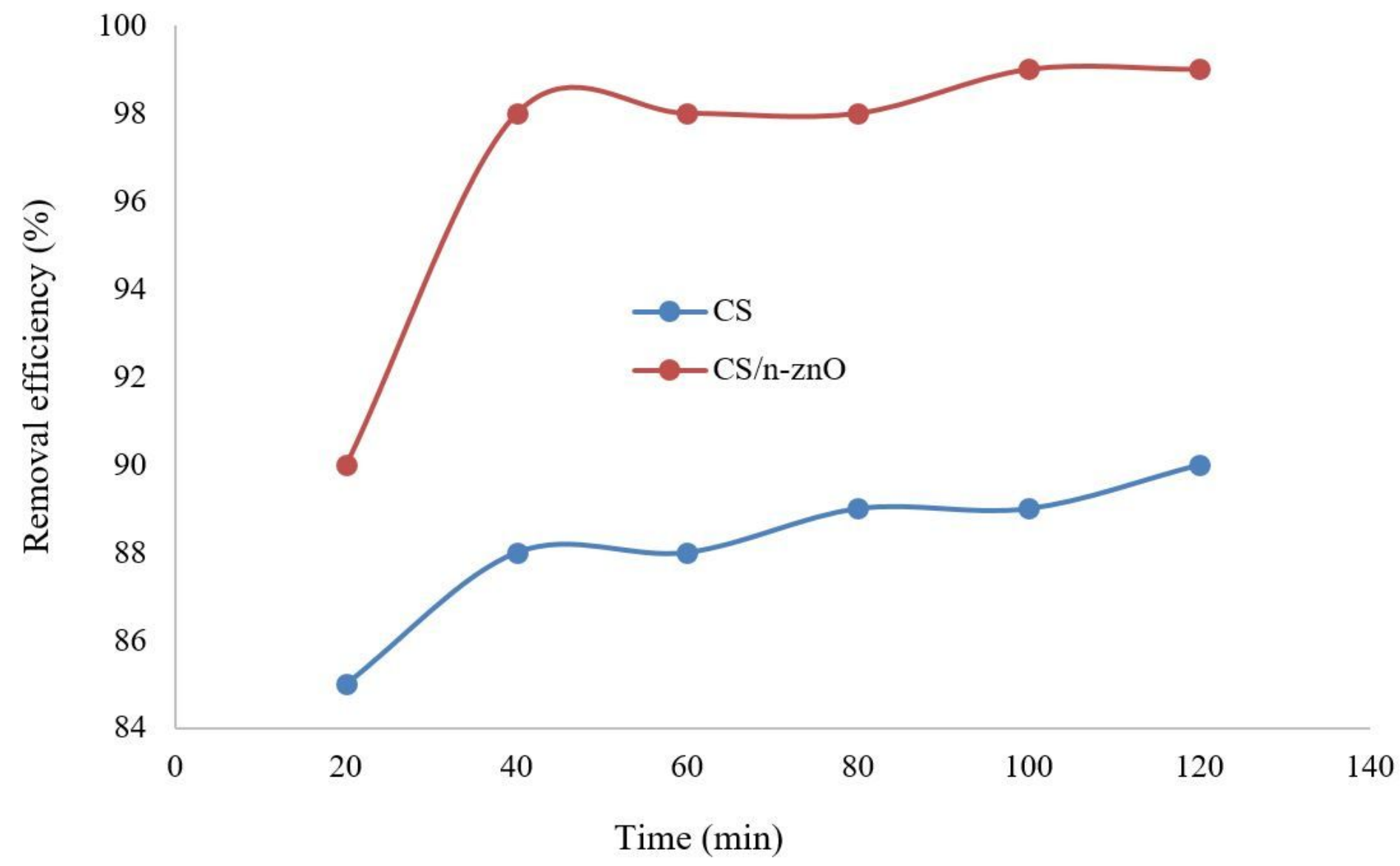

\section{Figure 7}

The effect of time on the surface adsorption process under specific conditions (solution volume:100 mL, adsorbent mass: $0.01 \mathrm{~g}$, initial dye concentration: $50 \mathrm{mg} / \mathrm{L}$, temperature: $25^{\circ} \mathrm{C}, \mathrm{pH}: 4$, and stirrer speed: 200 rpm). 


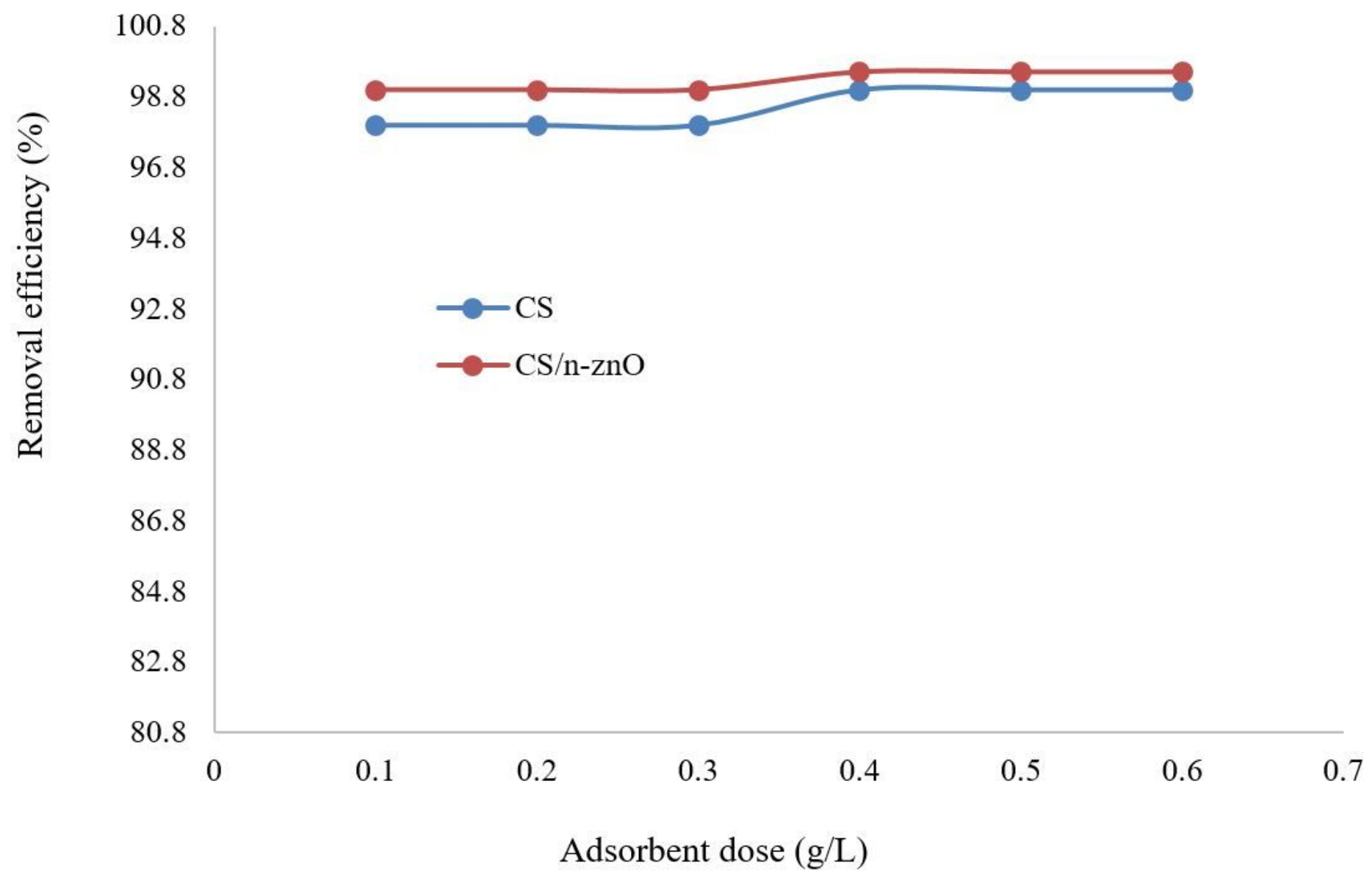

Figure 8

Effect of adsorbent amount on surface adsorption process on the adsorbent (CS/n-ZnO) under specific conditions (solution volume: $100 \mathrm{~mL}, \mathrm{pH}: 4$, initial dye concentration: $50 \mathrm{mg} / \mathrm{L}$, temperature: $25^{\circ} \mathrm{C}$, time: $40 \mathrm{~min}$, and stirrer speed: $200 \mathrm{rpm}$ ). 


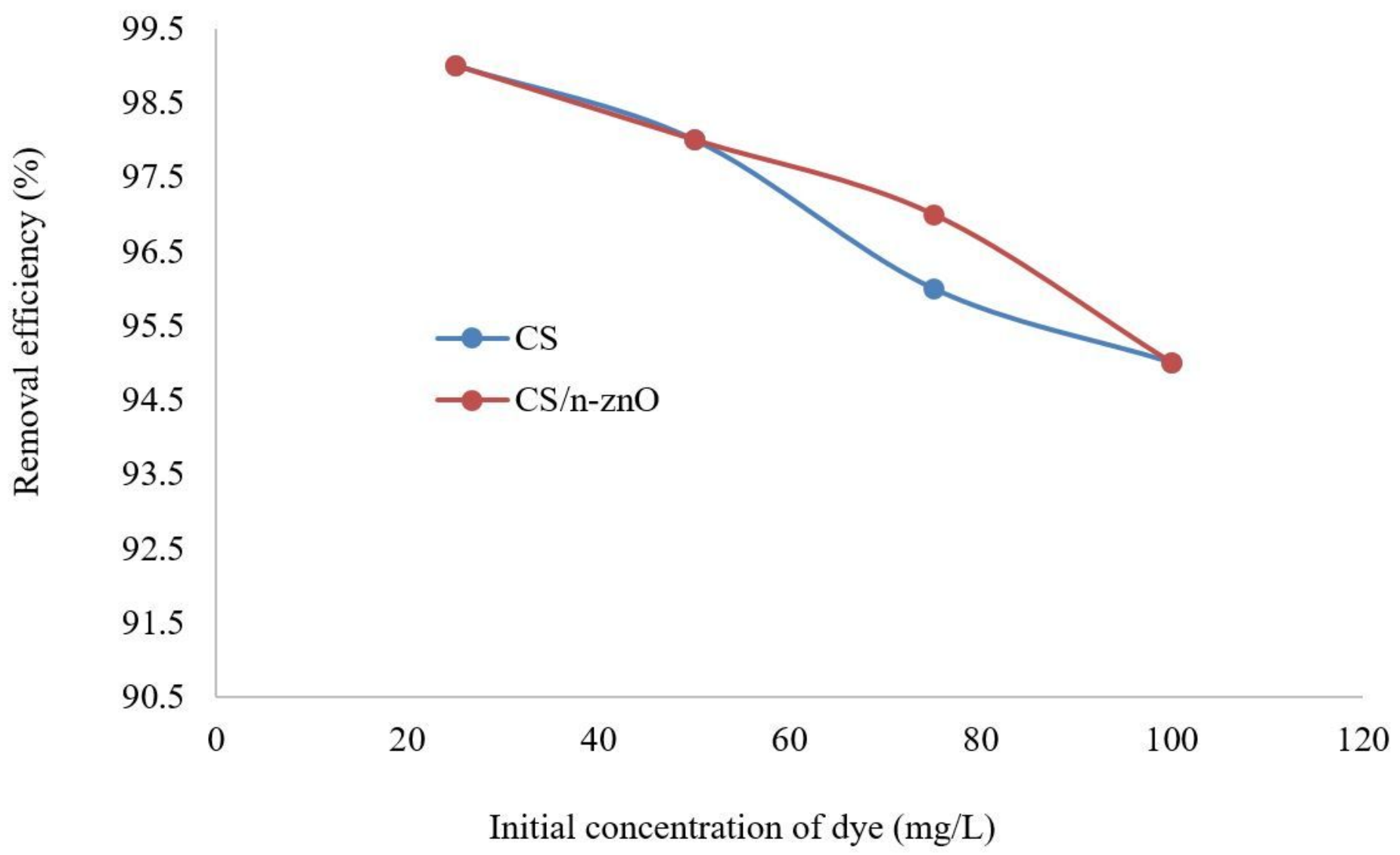

Figure 9

The effect of initial dye concentration on the adsorption process under specific conditions (solution volume: $100 \mathrm{~mL}$ of, adsorbent mass: $0.01 \mathrm{~g}$, pH: 4, temperature: $25^{\circ} \mathrm{C}$, time: $40 \mathrm{~min}$, and stirrer speed: 200 rpm). 


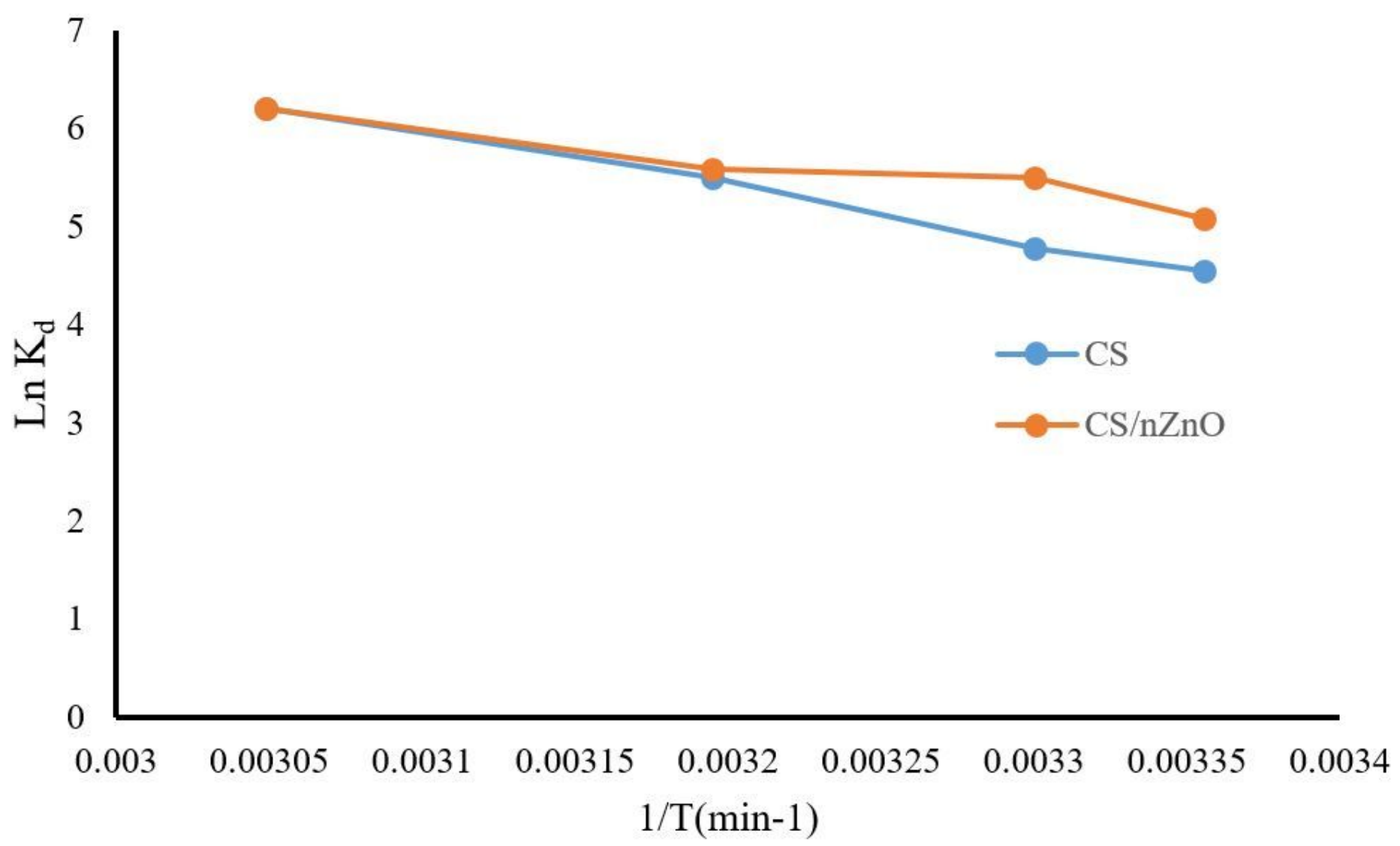

Figure 10

Linear plot of In kd vs. 1/T for adsorption of RR 198 dye on CS and CS/nZnO 